\title{
Los códices modelo y los manuscritos hebreos bíblicos españoles
}

\author{
M. ${ }^{\text {a }}$ Teresa ORTEgA MONASTERIO* \\ Instituto de Filología - CSIC, Madrid
}

Es tradicional la importancia de los manuscritos hebreos bíblicos españoles $\mathrm{y}$, debido a ello, algunos fueron utilizados en la composición de famosas biblias, como la Políglota Complutense o la Biblia Regia. Y también se debe a la misma causa que una buena parte de los trabajos desarrollados por los investigadores del CSIC dedicados a la Biblia se centren en el estudio de estos manuscritos, de sus características y de su catalogación. Entre estos códices se encuentran valiosos ejemplares, tanto de biblias como de manuscritos de otras materias.

No son muchas las biblias completas que se encuentran en las bibliotecas españolas. Baste decir que solamente contamos con seis ejemplares entre todos los de las bibliotecas madrileñas, a pesar de que son las más completas, como la Biblioteca del Monasterio de El Escorial, la Biblioteca Nacional o el fondo antiguo de la Universidad Complutense. Entre estas biblias tenemos el ya conocido manuscrito M1 de la Biblioteca de la Universidad Complutense de Madrid, cuyas masoras del Pentateuco hemos publicado recientemente. Pero también

*monasterio@ filol.csic.es

Sefarad 65 (2005) págs. 353-383

(c) CSIC

ISSN 037-0894 
hay otros códices de importancia que tienen algunas características peculiares que afectan a sus masoras.

En primer lugar, la masora puede ofrecer información que va más allá de la generalmente recogida. Es decir, en algunas ocasiones la masora de estos manuscritos, además de indicar el contenido típico masorético, alude a las especiales lecturas de algunas palabras en los llamados códices modelo.

Sabemos que los masoretas copiaban cuidadosamente el texto de la Biblia y, conscientes de que existían variantes entre los distintos manuscritos, se preocupaban especialmente de corregir su texto de acuerdo con otros códices de reconocida excelencia. A veces, expresaban la exactitud de sus copias bien en los colofones de los manuscritos, bien en los márgenes del texto, en forma de nota masorética, citando a menudo el códice que habían seguido para una u otra lectura. Unas veces, estas citas apoyaban simplemente la lectura del códice y otras veces ofrecían otra lectura distinta, pero a su vez acreditada por otro manuscrito famoso.

Los códices modelo, aunque no han llegado hasta nosotros, son conocidos por las referencias en las que aparecen. Algunos son muy famosos, como el Codex Hil.lelî, el Yěrûsălmî̀, el Zambuki, o el Jericó. Existe otro muy citado que es el Codex Mûggah, aunque autores como A. Dotan opinen que no es un códice en concreto, sino que simplemente se refiere ha un códice correcto cualquiera. Dice textualmente: «The term Sefer Muggah does not apparently refer to a specific book» ${ }^{1}$. Pero otros autores, como Ginsburg, defienden la existencia de un Codex Mûggah, como lo demuestran sus palabras:

The earliest codex quoted by the Massorites, as far as I can trace, is the Mûggah ${ }^{2}$,

o más adelante:

\footnotetext{
1 Encyclopaedia Judaica, vol. XVI (1971) col. 1423, sub voce Masorah.

2 Ch. D. Ginsburg, Introduction to the Massoretico-Critical Edition of the Hebrew Bible (New York 1966) pág. 429.
} 
In the St. Petersburg codex of A.D. 916 which exhibits the next oldest Massorah, the authority of the Codex Mûggah is appealed to in no fewer than eight instances in support of particular readings (...) The Codex Mûggah is henceforth to be found referred to as an authority in almost every MS. of importance either by the full title Codex Mûggah (ספר מוגה) or simply in the Mûggah (במוגה), Mûggah (מגה)» ${ }^{3}$.

Efectivamente, ya se refiera a un códice en concreto, ya se refiera a uno de los códices correctos, el hecho es que aparece muy a menudo citado en los márgenes de los manuscritos como una referencia de prestigio.

Para esta ocasión, y para que sirva solamente como una muestra, he seleccionado algunos manuscritos españoles valiosos ${ }^{4} \mathrm{y}$ he comprobado en los libros del Pentateuco las notas que aparecen en sus masoras acerca de estos códices modelo. Hay que decir que precisamente los manuscritos M1 y Or 2201, los dos más antiguos, son los que contienen menos referencias en su Pentateuco a estos códices y, curiosamente, todas ellas son de segunda mano. En los casos en que hay discrepancia entre las lecturas se comparan éstas con las de los manuscritos B19a de Leningrado (L) y con el Or 4445 del British Museum y se cita la opinión que sobre ello tienen los comentaristas Menahem de Lonzano y Y. Šelomoh de Norzi en sus respectivas obras ' $\hat{O} r$ Torah y Minhat $\underline{\text { Śay }}{ }^{5}$. Las variantes aparecen clasificadas atendiendo a su naturaleza dentro del apartado correspondiente a cada manuscrito. Al final, se ofrece una lista de todas las variantes con el texto exacto de su masora y del códice correspondiente. En dicha lista, se señalan con un asterisco los pasajes que han sido previamente comentados.

\footnotetext{
${ }^{3}$ Ch. D. Ginsburg, Introduction..., págs. 430-431.

${ }^{4}$ Tres de ellos, M1, M2 y G-II-8, se conservan en bibliotecas españolas. Los otros dos, Or 2201 y Or 2626-28, pertenecen a la British Library.

${ }^{5}$ Para la traducción del Minhat $\breve{S}$ ay he utilizado la traducción inédita de la Dra. M. ${ }^{\text {a }}$ Josefa de Azcárraga Servert, y para la del Ốr Torah la mía propia.
} 


\section{G-II-8 ${ }^{6}$}

En primer lugar, he trabajado con el ms. G-II-8 de la Biblioteca de El Escorial. Dicho manuscrito, datado en el siglo xv, procede de la colección de Arias Montano y estuvo depositado en el convento de Santiago de la Espada o de los Caballeros en Sevilla, hasta que fue llevado a El Escorial en 1602. Contiene toda la Biblia y está escrito en una bella escritura cuadrada sefardí, con iluminaciones en dorado y varios colores con motivos geométricos y vegetales. Su masora se incluye solamente en los libros del Pentateuco, excepto en los folios 14r-18r. La masora parva (en adelante MP) se presenta en los espacios intercolumnares y la masora magna (en adelante $\mathrm{MM}$ ) en dos líneas en el margen superior y tres en el inferior, como es habitual, a veces con motivos geométricos y vegetales. Tiene varias notas en tinta roja de mano de Alfonso de Zamora.

En la masora de su Pentateuco cita códices modelo o códices anónimos. Se cita el Sefer Mûggah en siete ocasiones, de las que cinco se refieren a una variante vocálica. En una de ellas podemos tener una pista de que el masoreta consideraba que el citado Sefer Mûggah no era un códice concreto, sino que podía referirse a varios códices distintos, lo que daría la razón a A. Dotan. Dice en Num 21,24, acerca de la palabra i⿱丷: «en el Sefer Mûggah se encuentra 꾸 con qames, pero en otro Sefer Mûggah lo he encontrado con patah...»

En otros casos, la masora da noticias contradictorias acerca de un mismo códice. En Ex 37,24, el segundo kaf de la palabra vocaliza con qames, y dice la masora del manuscrito G-II-8: «En el Sefer Mûggah está escrito con patah porque va en estado constructo». Sin embargo, en la masora de Ginsburg se anota que vocaliza con qames en el Mûggah ${ }^{7}$. L y Or 4445 puntúan con qames, igual que

\footnotetext{
${ }^{6}$ Para una descripción detallada del ms. véase F. J. DEL BARCO DEL BARCO, Catálogo de manuscritos hebreos de la Comunidad de Madrid (Madrid 2003) vol. I, págs. 124-126 y M. ${ }^{a}$ J. DE AzCÁrRAGa SERVERT, E. FERnÁndeZ TEJero Y M. ${ }^{a} \mathrm{~T}$. ORTEga Monasterio, El manuscrito hebreo bíblico G-II-8 de la Biblioteca de San Lorenzo de El Escorial (Madrid 2000).

7 Ch. D. GinsBurg, The Massorah Compiled from Manuscripts (New York 1975) I, pág. $607 \S 657$.
} 
M1 y Or 2201. Pero Ben Hayyîm ${ }^{8}$, M2 y Or 2626-28 tienen patah; en este último dice su masora: «En el Zambuki se vocaliza con qames». En este caso coincide la vocalización de los dos manuscritos españoles más antiguos por un lado y la de los dos más modernos por otro.

Otro de los códices citados en este manuscrito es el Codex Hil-lelí. Este códice, también perdido, es uno de los más importantes y de los más citados. Según Abraham Zacuto, fue escrito por Rabí Hillel alrededor del año 600 y de ahí su nombre. Ginsburg cita la crónica de Zacuto en los siguientes términos:

In the year 4957 A.M. on the 28th. of Ab (14th., August 1197) there was a great persecution of the Jews in the Kingdom of Leon from the two Kingdoms that came to besiege it. At that time they removed thence the twenty-four sacred books which were written about 600 years before. They were written by R. Hillel b. Moses b. Hillel and hence are called after his name the Hilleli Codex. It was exceedingly correct and all other Codices were revised by it. I saw the remaining two parts of it containing the Former and Latter Prophets written in large and beautiful characters which were brought by the exiles to Portugal and sold at Bugia in Africa where they still are, having been written about 900 years ago. Kimchi in his Grammar on Numb XV 4 says that the Pentateuch of the Hillel Codex was extant in Toledo ${ }^{9}$.

De hecho, Ginsburg cita también dos ocasiones en que encuentra mencionado en un manuscrito el Hil·lelí de León, en dos pasajes de Reyes y Jeremías, en el ms. Add. 15251 del British Museum ${ }^{10}$. Frecuentemente, se ha identificado el Codex Hil-leli con el ms. 44a del Jewish Theological Seminary de New York, aunque el Prof. Goshen Gottstein mantenía que no debía identificarse uno con otro ${ }^{11}$.

El Hil-lelí se cita en el manuscrito G-II-8 cuatro veces en el libro del Génesis y una en Éxodo. En todas las ocasiones la variante es de

\footnotetext{
${ }^{8}$ Biblia Rabinica. A Reprint of the 1525 Venice Edition, Edited by Jacob ben Hayyim Ibn Adoniya. Introduction by Moshe GosHEN-GoTTSTEIN (Jerusalem 1972).

${ }^{9}$ Ch. D. GinsBurg, Introduction..., págs. 431-432.

${ }^{10}$ Los pasajes son 1 Re 1,18 y Jer 5,6.

11 M. Goshen-Gottstein, «Biblical Manuscripts in the United States», Textus 2 (1962) pág. 45.
} 
carácter vocálico y en dos de los casos se compara al mismo tiempo con otro de los códices modelo: en el primer caso, Gen 49,22, acerca de la palabra פָَ se compara con el Mûggah. Dice su masora: «en el Hil.lelí, todos los casos son con qames, pero en el Sefer Mûggah y en la masora magna se encuentra con patah hasta que venga y os enseñe la justicia (Os 10,12)». Al referirse a todos los casos alude a los dos en los que aparece la palabra en el mismo versículo. Sin embargo, en la MM del manuscrito no aparece nota acerca de la palabra. Parece que la vocalización más correcta es con qames, como también vocalizan L, Or 4445, M1, M2, Or 2626-28 y Or 2201 en los dos casos en que la palabra aparece en el versículo. Esta misma puntuación es considerada correcta por Lonzano y Norzi en sus obras. Dice Lonzano: «En ambos casos el reš con qames»; y Norzi escribe: «En ambos casos el reš es con qames en la mayoría de los códices manuscritos y en las ediciones antiguas, y así lo escribió también el 'Ôr Torah».

El segundo caso en que la masora contrasta las lecturas de dos códices modelo es Gen 18,17, acerca de la palabra הַמְ cuya nota

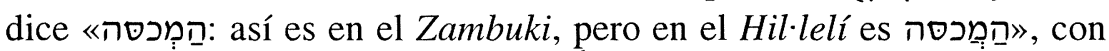
hatef patah en lugar de šěw' en el mem. Lonzano afirma en su 'Ôr Torah que el mem se vocaliza con hatef patah. Los códices, L y Or 2626-28 vocalizan de igual manera; Or 2201 tiene el texto borroso y M1 y M2 tienen solamente š̌wa'.

Una de las variantes, la correspondiente a Ex 30,14 en la palabra מִבְּ, está recogida en Ginsburg ${ }^{12}$ como variante del Hil.lelí, coincidiendo en la información que ofrece el manuscrito G-II-8, que afirma que en el citado códice vocaliza el bêt con sêrê en vez de segốl y lleva acento mêrkả en lugar de tẹbûir.

Pero el códice más citado en este manuscrito es el Zambuki, que aparece en ocho ocasiones, seis en Génesis y dos en Números, y también se refiere en todos los casos a variantes de puntuación. El nombre de este códice responde probablemente al de la comunidad

${ }^{12}$ Ch. D. GinsBurg, The Massorah..., I, pág. $605 \S 648$. 
que lo poseía, en Zambuki. Sus lecturas se ofrecen a menudo ligadas a las del Hilllelí. Esto ocurre, como hemos visto, en Gen 18,17, a

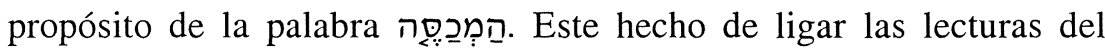
Zambuki con las del Hil-lelí también ocurre en otros manuscritos españoles, como el 2626-28 del British Museum en varias ocasiones, como veremos más adelante ${ }^{13}$.

Existe un último códice citado en Num 11,1 al hablar del Zambuki, y es «el manuscrito antiguo»: probablemente no se refiera a un códice en concreto, sino simplemente a un códice antiguo y acreditado. Dice la nota a este pasaje: «En el Zambuki y según el qadmonî,

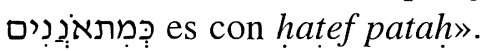

Por último, aparecen citados en este manuscrito algunos códices anónimos, unas veces comparándolos con otros códices y otras como única referencia. Ejemplo del primer caso lo encontramos en Gen 4,13, al referirse a la palabra מנשא, cuya nota dice: «hay códices exactos en los que מנשא se escribe defectivo, pero en el Sefer Mûggah se escribe pleno y su masora dice que aparece 12 veces en la Torá». En este caso sí parece que al citar el Sefer Mûggah se cita un códice concreto. En relación con otro códice modelo, el Hil·lelí, se cita este caso en el Eben Safir ${ }^{14}$. En él se recoge una lista de lecturas atribuidas al Codex Hillelí; en ella, aparece este caso donde también se le atribuye a este códice la lectura plena. Sin embargo, se atribuye la lectura defectiva al Codex Yěrûsălmî, lectura apoyada por L y Ben Hayyîm. También Ginsburg ${ }^{15}$ recoge esta variante al hablar de las variantes atribuidas al Mûggah, coincidiendo con la información del ms G-II-8. Norzi anota en su Minhat $\underline{S}$ Say la noticia, apoyando el

\footnotetext{
${ }^{13}$ Véase más adelante pág. 366.

${ }^{14}$ Eben Saphir. Beschreibung des Reisen des Rabbi Jacob Saphir aus Jerusalem durch Egypten, Arabien, Jemen, Aden, Ostindien und Australien. II Theil (Mainz 1874) pág. 200. Esta obra describe los viajes de Jacob Safir y contiene un capítulo dedicado a las lecturas plenas y defectivas del Sefer Hil-lelí, donde también aparecen citados el Yěrûśalmî y el Zambuki como códices modelo. El autor afirma haber encontrado un fascículo (quntres) encuadernado en una Biblia del siglo XI que se encontraba en la gran biblioteca de París y que contiene una lista de lecturas atribuidas al Codex Hil.lelí.

${ }^{15}$ Ch. D. Ginsburg, The Massorah..., I, pág. $607 \S 657$.
} 
texto pleno para la lectura del Hilleléi. También cita el Yěrûsălmî y el Sefer 'Ezra para indicar que lo escriben defectivo. Lonzano, en el 'Ôr Torah, expresa la misma opinión para el Hil lelí. Las lecturas de M2, Or 2626-28 y Or 2201 son plenas, pero la de M1 es defectiva, y dice su masora: «caso único y escrito defectivo».

Tenemos otros tres casos en los que se alude a códices notables. En Gen 31,26, en la palabra, כשכבי ת dice su masora: «en otros códices escrito pleno, כשביות》, y en Deut 21,10 dice respecto a איבֶיך: «en códices exactos, escrito pleno».

El caso más relevante es el de Gen 25,6, acerca de la palabra הפילגשים. Dice su masora: «Hay discrepancia al respecto. He encontrado en códices correctos הפילגשם sin el último yôd y no será enmendado hasta que llegue Elías». Con esta expresión se indica un tiempo indefinido. Se trata en este caso de una variante muy conocida entre los comentaristas, ya que la diferencia estriba en si se está aludiendo a una sola de las concubinas de Abraham o a las dos. En general, los comentaristas se inclinan por la escritura plena, con el yôd que indica el plural. En el Massoreth Ha-Massoreth de Elías Levita se indica respecto de esta variante:

The rule is that all the plurals of both participles and nouns, which have not two Chireks following each other, are written fully, except

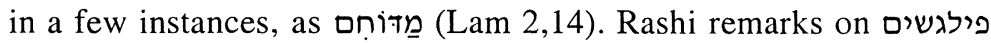
(Gen 25,6), that it is defective, which is taken from Bereshit Rabba, is contrary to the Massorah, for the Massorites mark it twice plene ${ }^{16}$.

Tanto Norzi como Lonzano señalan en sus trabajos que la lectura del Hil.lelí es doblemente plena. Los textos de L y M2 son doblemente plenos; pero Or 2626-28 es defectivo, y dice su masora: «Una sóla vez y defectivo, pero en algunos códices es pleno». También es defectivo en Or 2201 y M1, aunque en este último era pleno en primera mano.

\footnotetext{
${ }^{16}$ The Massoreth ha-Massoreth of Elias Levita... and Critical and Explanatory Notes by Christian D. GinSBURG (London 1867) pág. 158.
} 
M1 17

Este manuscrito pertenece a la colección de la Biblioteca de la Universidad Complutense de Madrid y fue utilizado como base del texto hebreo de la Biblia Políglota Complutense. Está escrito en letra cuadrada sefardí a tres columnas; la masora parva ocupa los márgenes intercolumnares y la masora magna tres líneas en el margen superior y cuatro en el inferior, en muchos casos ornamental con dibujos florales o geométricos. Tiene algunas viñetas iluminadas en oro $\mathrm{y}$, según su colofón, fue copiado en 1280 en Toledo. Este manuscrito ha sido objeto de numerosos estudios y su masora está siendo publicada por nuestro equipo de Biblia Hebrea del Instituto de Filología del CSIC.

De los manuscritos aquí estudiados, es uno de los más antiguos y también uno de los que recoge menos noticias alusivas a códices modelo en su Pentateuco. Solamente los libros de Levítico y Deuteronomio tienen alguna referencia, cuatro en el primer caso y cinco en el segundo. Curiosamente, todas ellas están escritas de segunda mano, con letra muy distinta del resto de la masora, mucho menos cuidada. Esto mismo ocurre con el otro manuscrito más antiguo consultado, el Or 2201, como veremos más adelante.

En un caso correspondientes al libro de Levítico, el texto aparece corregido para adecuarlo al de la masora. Se trata de Lev 14,49, en la palabra וٕאזique en primera mano era pleno. Y dice su MP: «en el Mûggah וְٕאi es pleno». Ginsburg anota en su Biblia ${ }^{18}$ que también es pleno en el Hilllelí y en el Yěrûsăalmî̀. Tanto L como Or 4445, G-II-8, M2 y Or 2201 presentan el texto defectivo. Norzi escribe que en una copia del Hilllelí es defectivo, pero que en el Yěrûsălmî es pleno. Lonzano afirma que es defectivo, sin especificar en qué fuentes. Sin embargo, Or 2626-28 tiene la lectura plena y dice su masora: «pleno en todos los casos menos dos».

${ }^{17}$ Para una descripción detallada del ms. véase F. J. DEL BARCO DEL BARCO, Catálogo de manuscritos... (Madrid 2003) vol. I, págs. 109-112.

${ }^{18}$ CH. D. Ginsburg, Biblia Hebrea. Definitely Revised According to the Masorah and the Early Editions with the Various Readings... by _ 4 vols. (London 1926). 
Los otros casos son: Lev 4,31, refiriéndose a la vocalización de la palabra חֶֶ, donde la masora indica que en el Mûggah es con segôl

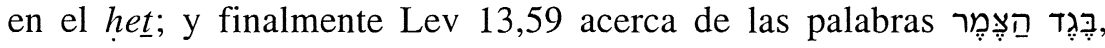
cuya masora indica que el Mûggah tiene esta misma lectura.

Y por último, Lev 26,39, en la palabra איביכם, aunque el texto está corregido: en primera mano estaba escrito איביהם con hê. En la nota de MP dice que el Mûggah es así, con kaf en lugar de hê. También Ginsburg recoge esta variante del Mûggah en su masora ${ }^{19}$, y el aparato de BHS ${ }^{20}$ indica que el qěrê del Mûggah y en muchos otros manuscritos es con hê. Los textos de L, Or 4445, G-II-8, Or 2626-28 y Or 2201 lo escriben con kaf. Pero M2 lo escribe con hê sin masora alguna. Norzi tiene una larga explicación que dice: «En un Pentateuco editado en Sabioneta está escrito con hê, pero los códices están equivocados y R. Me'ir Todros Abulafia, de bendita memoria, nos quitó este tropiezo ${ }^{21}$ al escribir lo que sigue: איביכם tres veces defectivo de waw y pleno de yố y sus simanîm son והנשארים el primero;

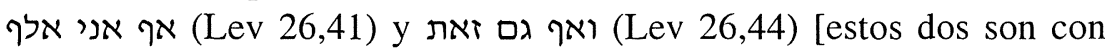
hê]. Se deduce de esta lista que והנשארים es el último איביכם escrito con kaf. Los texto correctos también establecen que los textos en los que está escrito איביהם de והנשארים con hê, están equivocados».

Más son los casos que aparecen en el Deuteronomio. Cuatro de ellos se refieren al Sefer Mûggah y solamente uno al Hil·lelí. Se trata de Deut 32,24, acerca de las palabras ושִן־בהמות, cuya nota dice que en el Hil.lelí vocaliza el sim con segôl. L y Or 4445 vocalizan con segôol, pero los códices españoles tienen șêrê. Los otros cuatro casos hacen referencia cada uno a una característica distinta.

Como variante consonántica tenemos, en Deut 3,16, la partícula עַ (la primera del versículo) anota que «en el Mûggah se escribe Tالإ)». El texto de M1 era en primera mano con waw que ha sido borrado y

19 Ch. D. Ginsburg, The Massorah..., I, pág. $607 \S 657$.

${ }^{20}$ Biblia Hebraica Stuttgartensia... ediderunt K. ElligER et W. RudolPH. Textum Masoreticum curavit H. P. RÜGER. Masoram Elaboravit G. E. WEIL (Stuttgart 1984).

21 Véase Is $57,14$. 
añadida la nota masorética. Los demás manuscritos, como L y Or 4445 lo escriben con waw; lo mismo ocurre en los otros manuscritos españoles aquí estudiados, excepto Or 2626-28, que lo escribe sin waw, aunque lo tenía en primera mano, como ocurre con M1. Por lo tanto, en este caso la cita del códice modelo se ha puesto para llamar la atención sobre la corrección en el texto de M1. De nuevo coinciden las lecturas de los dos manuscritos españoles más antiguos, incluso en la de su primera mano.

Acerca de escritura plena o defectiva, en Deut 28,1 , en la palabra עַin dice su nota: «en el Mûggah se escribe defectivo». Sin embargo, en otras fuentes como la Masora de Weil ${ }^{22}$, los casos defectivos de esta palabra son cinco, entre los que no se encuentra este pasaje. También en L, Or 4445, G-II-8, M2 y Or 2201 se escribe pleno. Sin embargo, Or 2626-28 es defectivo.

Finalmente, afectando a la puntuación, tenemos un caso en Deut

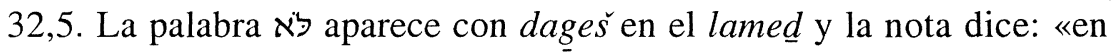
el Mûggah es con rafeh». Sin embargo, esta palabra tiene una segunda MP, que no es de segunda mano como la anterior, que indica: «cuatro veces con dageš; así apoya la lectura de todos los códices españoles aquí tratados. También aparece esta palabra con nota masorética en el manuscrito M2. Su texto es con dageš y la nota dice: «dageš en el Sefer Mûggah». Por lo tanto, contradice la información que ofrece la masora de M1. En este caso, también podría pensarse que se refiere a dos códices correctos distintos.

$\mathrm{M} 2{ }^{23}$

Se trata de un manuscrito conservado en la biblioteca de la Universidad Complutense de Madrid y fechado en 1482, según su colofón. Contiene toda la Biblia hebrea y está escrito en dos columnas con letra cuadrada sefardí y copiado en Tarazona por Yom Tob ben

${ }^{22}$ G. WeIL, Massorah Gedolah (Roma 1975) lista 1115. Los casos que aparecen son Ex 22,22; Deut 1,16; 11,13; 1 Sam 23, 10 y Jer 17,24.

${ }^{23}$ Para una descripción detallada del ms. véase F. J. DEL BARCO DEL BARCO, Catálogo de manuscritos... (Madrid 2003) vol. I, págs. 113-115. 
Yishaq Amarillo para él mismo. Su MP ocupa los márgenes intercolumnares y la MM dos líneas del margen superior y tres del inferior, en ocasiones formando dibujos geométricos. Los encabezamientos de los libros están iluminados en forma de viñeta conteniendo la letra o palabra inicial en dorado y colores, con adornos de motivos vegetales. Como los manuscritos G-II-8 y M1, tiene varias anotaciones de mano de Alfonso de Zamora (nombre latino de los libros, división capitular, etc.), generalmente en tinta roja. También hay una nota suya al final del rollo de Antíoco, fechada el uno de marzo de 1520, en hebreo. La importancia de este manuscrito radica también en haber sido utilizado para la composición del texto hebreo de la Biblia Políglota Complutense.

Este códice hace referencia exclusivamente al Sefer Mûggah en 16 ocasiones a lo largo del Pentateuco y con alusiones en todos sus libros. Las notas son escuetas, sin referencias a otros códices. Algunas veces se refiere a más de una variante, como ocurre en Gen 4,4 y Num 34,28. En el primer caso, acerca de la palabra ומחלב̆הן dice su masora: «dos veces en la Torah escrito defectivo y el bêt con rafeh, pero en el Sefer Mûggah está con rafeh y pleno». Es decir, en una de las variantes el Mûggah ratifica la lectura del códice, pero en el otro caso discrepa.

La lectura de L coincide con la de este manuscrito y con G-II-8, M1, Or 2626-28 y Or 2201. Norzi solamente indica que el bêt lleva rafeh.

El caso de Num 34,28 se refiere a la palabra פדהָאל. Su masora anota: «caso único y escrito en una sola palabra y el hê va puntuado con š̌wa’ en el Sefer Mûggah». En este caso, la nota ratifica la lectura del manuscrito al coincidir con la del códice de referencia. Norzi ofrece como correcta la lectura del hê con šěwa', añadiendo que en los códices correctos aparece escrito en una sola palabra. Así es también la lectura de los manuscritos aquí tratados, excepto G-II-8 que lo escribe en dos palabras ${ }^{24}$.

${ }^{24}$ M1 y Or 2626-28 añaden un mappîq en el hê. 
Cinco de las notas de M2 son claramente de segunda mano (las tres de Génesis, Num 34,28 y Deut 28,43). Generalmente, los contenidos de las notas son variados, aunque las que más abundan (seis casos) se refieren a lecturas plenas o defectivas. Hay también tres casos de variantes acentuales, tres vocálicas, tres que apoyan la lectura de su propio texto, dos que añaden rafeh o dageš y otra, ya vista, que especifica si se deben escribir en una o dos palabras.

En una de las ocasiones, Ex 36,7, acerca de la palabra והמלאלה, la nota contradice el texto del manuscrito. Éste va acentuado con zaqef y la nota dice: «con rěbî́a en el Sefer Mûggah». La lectura de los otros manuscritos españoles, así como L y Or 4445, coincide con la indicada para el Mûggah, dejando solo el texto de M2.

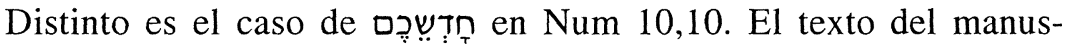
crito coincide con la información que da la nota acerca del Codex Mûggah, diciendo que se escribe defectivo; también ésta es la opinión de Norzi. Sin embargo, M1, L y Or 4445 tienen su texto con escritura plena. Es defectivo el texto de Or 2201, sin nota alguna. También los textos de G-II-8 y de Or 2626-28 son defectivos, aunque ambos eran plenos en primera mano. La masora de G-II-8 está borrada, aunque todavía puede leerse «dos veces pleno»; y la masora de Or 2626-28 anota: «En el Mûggah es defectivo» ${ }^{25}$.

\section{Or $2626-28{ }^{26}$}

Se trata de uno de los mejores manuscritos sefardíes existentes y se conserva en la British Library. Consta de tres volúmenes, escrito en pergamino y a dos columnas en cuidadísima letra cuadrada sefardí, con iluminaciones, conteniendo toda la Bilblia Hebrea. La MM ocupa dos líneas en el margen superior y tres en el inferior y la MP los márgenes y espacios intercolumnares. La primera palabra de cada

\footnotetext{
25 Vid. infra.

${ }^{26}$ Para una descripción detallada del ms. véase Ch. D. GinsBuRg, Introduction..., págs. 707 ss.
} 
libro está escrita en mayor tamaño y con adornos que se extienden a lo largo de la columna. Los primeros veintidós folios contienen diversas listas masoréticas; también aparecen listas similares al final del manuscrito, todas ellas con bellas iluminaciones. El colofón que aparece en el fol. 185v indica que fue escrito en Lisboa en el mes de kislev de 1483.

La masora cita en numerosas ocasiones varios códices modelo. Ya señalaba Ginsburg que citaba conjuntamente el Codex Hil·lelí con el Zambuki ${ }^{27}$. En seis ocasiones se hace referencia a más de un codice modelo en una misma variante: en Deut 30,7 se cita conjuntamente el Hil·lelí, el Zambuki y el Mûggah.

En total aparecen 108 casos en el Pentateuco que hacen referencia a códices modelo, distribuidos en los cinco libros bíblicos que lo componen. El estilo de las notas es similar a las del códice M2: son escuetas pero sin llegar al extremo del M1 o del Or 2201. Es decir, presenta similitudes con otros códices de la misma época. El Codex Mûggah se cita en 28 ocasiones, el Hil·lelí en 33 y el Zambuki en 55. La mayoría de las variantes son de carácter vocálico (75), seguidas por las que se ocupan de la acentuación (20) y de escritura plena o defectiva (3). Hay diez casos que se refieren a otros temas o en los que no se especifica claramente a qué se alude en la variante.

Solamente se registran tres notas que aparecen también en otros códices: los pasajes de Ex 30,14, con referencia a la palabra מִכָכ),

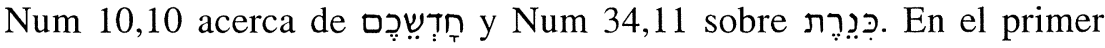
caso, la información coincide con la ofrecida en la masora del manuscrito G-II-8 acerca del Hil.lelí, aunque omite el detalle de la acentuación, siendo más escueta. En el segundo caso, la información es la misma, tanto aquí como en M2. Pero hay que señalar que el texto del manuscrito Or 2626-28 era pleno en primera mano. Es decir, ha sido corregido para hacerlo coincidir con la masora. Lonzano anota en el 'Ôr Torah: «en el Hil·lelí es pleno, pero en los códices correctos de

${ }^{27}$ CH. D. Ginsburg, Introduction..., pág. 433, n. 1. 
Sefarad el texto es defectivo». Sin embargo, los manuscritos españoles que aquí se tratan son mayoritariamente de texto pleno.

Entre todos los casos que se refieren a puntuación, solamente cuatro aluden al rafeh o dages. Son Gen 45,10, Lev 13,2, Deut 12,11 y 34,4. Los dos primeros aluden al Codex Zambuki, el tercero al Hil.lelí y el cuarto a ambos. En el caso de Lev, acerca de la palabra אחice la nota que en el Zambuki ha sido borrado el rafeh para poner un dages. La nota del pasaje de Deut 12,11 es más extensa. Acerca de la palabra תזרו señala que es con rafeh, y que hay otro caso de forma similar, la palabra ותتצו de Is 22,10 , y que en el Hil.lelí es también así. Norzi tiene una nota acerca de este caso: «en los códices correctos el dalet lleva dages (...) pero en los textos manuscritos de Sefarad he visto en sus márgenes que en el Hillelí el dalet es con rafeh. También en el Miklôl (...) se dice citando a Yaqob ben Eleazar que en el Sefer Hilllelí que estaba en Toledo el dalet es con rafeh». El texto de los demás manuscritos españoles que tratamos aquí coinciden con estas noticias y puntúan con rafeh.

Encontramos cuatro casos en los que el texto del manuscrito ha sido corregido, dos haciendo referencia al Codex Mûggah, Gen 42,8 y Num 10,10 y dos al Hil-lelí, Lev 7,7 y Num 11,32. Acerca de la palabra הכרהו de Gen 42,8 dice su nota que, según el Mûggah, es palabra única y escrita defectiva, pero que una masora exacta especifica que hay un caso defectivo y uno pleno (Iob 2,12). El texto del manuscrito es actualmente defectivo, pero en primera mano era pleno, הכירהו. Los textos de L, Or 4445, M1, M2 y Or 2201 son defectivos. La masora de Or 4445 especifica: «caso único pero ולא הכירהו (Iob 2,12) es pleno». La masora de M1 dice: «son dos casos, uno defectivo y uno pleno» y da también el sîman de Iob 2,12 para el pleno. Por otra parte, la masora de M2 anota simplemente: «dos casos, uno es defectivo». El segundo caso que cita al Mûggah, Num 10,10 , ya está comentado más arriba.

En Lev 7,7 se cita al Hilllelí en la masora de כחטאת indicando que el têt vocalizaba con qames y ha sido corregido. Lo mismo ocurre en el manuscrito, que tenía qames en primera mano. Sin embargo, el 
resto de los códices españoles, así como L, vocalizan con qames. En el segundo caso, Num 11,32 acerca de la palabra השלו, se indica que en el Hil.lelí es pleno, השליו. M1 da como qeerê la lectura plena; también todos los demás manuscritos tienen el texto defectivo, incluso L y Or 4445.

Hay cinco pasajes bíblicos en los que se repite la noticia aunque afecte a distintas palabras. Se trata de Gen 49,8, Ex 14,28, Lev 16,8, Num 24,5 y Deut 31,28 . En realidad, deberían ser seis los pasajes (falta la nota en Gen 1,1), ya que se refiere a las palabras que deben escribirse a principio de página en la Torah. Dice la masora de todos ellos: «en el Mûggah va a principio de página y su siman es שביה שמ». Este siman está formado por las letras iniciales de estas palabras que deben estar al principio de la página: בראשית (Gen 1,1), יהודה (Gen 49,8), הבאים (Ex 14,28), שמור (Deut 12,28), מוצא (Deut 23,24) y (Deut 31,28) ${ }^{28}$. Norzi anota la misma información en el pasaje de Génesis 49,8 y en el de Levítico añade que las biblias de Roma sustituyen el pasaje de Levítico por Deut 12,28, y que en los códices de Sefarad se escribe a principio de página. Lonzano también corrobora esta afirmación en Lev 16,8. En el pasaje de Números, Norzi añade que también el Baial ha-T Turîm ${ }^{29}$ dice que estas palabras deben escribirse en esta forma. De los manuscritos aquí tratados, solamente M1 da esta noticia en el pasaje de Deut 12,28 y G-II-8 en Gen 49,8 , Deut 31,28 y 23,24 , pero en ninguno de estos casos se alude a los códices modelo.

En Gen 49,11, acerca de la palabra כָָָּ dice la masora que es un caso único y que en el Mûggah vocaliza con segốl. Norzi afirma que en la mayoría de los códices vocaliza con segôl, pero que el autor del

\footnotetext{
${ }^{28}$ Existe una segunda recensión de estas palabras que sustituye שמור por שני (Lev 16,8) y מה por (Num 24,5). Véase Ch. D. GinsburG, The Massorah..., IV, pág. 472. Acerca de este fenómeno en el ms. G-II-8 véase M. ${ }^{a}$ J. DE AZCÁRRAGA, «El manuscrito G-II-8 de El Escorial: estudio interno», en El Manuscrito Hebreo Bíblico G-II-8 de la Bilioteca de San Lorenzo de El Escorial (Madrid 2000) págs. 109-110.

${ }^{29}$ Jacob ben Ašer (1270?-1340), autor del 'Arba'a Tûrîm, obra que trata las leyes referentes tanto al individuo como a la comunidad. Véase Encyclopaedia Judaica, vol. IX (1971) cols. 214-216, sub voce Jacob ben Asher.
} 
'Ôr Torah dice que debe ser con șêrê. Efectivamente, en este pasaje Lonzano defiende la vocalización con sêrê y así vocalizan todos los manuscritos. También se refiere al mismo asunto el caso de Ex 20,19, respecto a la palabra דֶֶּ. La nota afirma que en el Mûggah es con sêrê. Sin embargo, tanto Norzi como Lonzano opinan que debe llevar segôl. El primero cita también que el autor del Liwyat Hen ${ }^{30}$ dice que la palabra debe llevar maqqef y segôl y así es en los demás manuscritos.

En Ex 29,43 la masora de la palabra ונקדש dice que se escribe una sola vez con patah pero que el Mûggah lo escribe con qames. Norzi señala precisamente lo contrario, que en algunos códices sefardíes lleva qames y que su masora anota que es caso único con qames. También Lonzano coincide con Norzi en la información. El resto de los códices, L, G-II-8, M1 y Or 2201 tienen patah, excepto M2 que vocaliza con qames. En este caso, solamente este manuscrito coincide con la información acerca de los códices de Sefarad.

En Num 5,28 se señala al margen que la palabra ונזרָעה vocaliza en el Hil lelí igual que en este manuscrito. Sin embargo, L y el resto de los códices españoles que aquí se mencionan vocalizan el reš con šěwa solamente. Norzi escribe acerca de esta palabra: «en el Šorašîm, raíz זרע, el reš solo lleva š̌wa'. En un texto manuscrito está escrito al margen: 'en el codex Jericó aparece ונזרעה con hatef qames en el reš'. También en el libro Rab Pe álîm, en la forma nif'al de los verbos fuertes, está escrito que en algunos códices ונקתה ונזרעה זרע se puntúa con hatef qames. Y así lo he visto yo también en algunos códices de Sefarad y en una edición antigua y así también lo escribió el autor del '̂́r Torah». Es decir, la lectura de Or 2626-28 queda avalada tanto por Norzi como por Lonzano.

La masora de לגלגלתם en Num 1,22 anota que el segundo lamed está prolongado por encima de los demás lamed en el Mûggah. Norzi señala que en los códices de Sefarad, el segundo lamed no se diferencia de los demás lamed de la Torá y añade que Lonzano se extiende

${ }^{30}$ Immanuel ben Yequtiel de Beneviento, Liwyat Hen (Mantua 1557). 
en este comentario. En el 'Ôr Torah escribe Lonzano: «cambió el editor la forma de este lamed haciéndolo alargado y remarcando la parte superior, y escribió que así debe ser, pero erró, pues no se trata del segundo lamed de גלגלתם, es decir, el tercero de לגלגלתם, sino del segundo lamed de לגלגלתם que es el primero de גלגלתם (לגלתם (...) y en el Hil-lelí y en los códices de Sefarad no hay mención alguna acerca de ésto; sólo en uno de los más famosos he encontrado escrito al margen: así es en el Mûggah, לגלגלתם y dice la masora que según la tradición de los orientales es más alargado que los demás... y se sobreentiende que los occidentales discrepan y opinan que este lamed es igual que los demás...» ${ }^{31}$. En los códices que aquí se estudian el lame $\underline{d}$ es igual al resto y no hay noticia alguna al respecto.

Deut 7,13 se refiere a la acentuación de la palabra שגר. Según la masora, el Mûggah no tiene maqqef, sino mĕhuppak. Tanto Norzi como Lonzano apoyan la lectura con maqqef, y así son también el resto de los códices: L, Or 4445, M1, M2 y Or 2201, cuya masora señala: «un solo caso con este acento». No es así G-II-8, que acentúa con měhuppak. La masora de M1, que es de una segunda mano, coincide con la de Or 2201 al decir que aparece una sóla vez con maqqef.

Ya hemos visto anteriormente casos en los que se cita en la misma noticia más de un códice modelo. En el manuscrito Or 2626-28 hay varios casos en los que se alude al Hil-lelí junto al Zambuki. Por ejemplo, en Gen 46,29 acerca de la palabra ויאסר dice su masora: «en el Hilleleli y el Zambuki puntúa con šěwa' en el 'alefi. Norzi corrobora esta puntuación al afirmar que, según el Miklôl, el 'alef solamente lleva š̌wa'. Los demás manuscritos puntúan de la misma forma, excepto M2, que carece de vocal en el 'alef.

El caso de Ex 21,37 se refiere a una diferencia entre Ben Ašer (en adelante BA) y Ben Naftalí (en adelante BN). Sobre la palabra -בר? ș se dice en su masora que hay diferencia entre BA, que puntúa

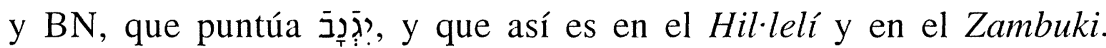

${ }^{31}$ M. ${ }^{\text {a }}$ T. Ortega Monasterio, Texto Hebreo Bíblico de Sefarad en el 'Ôr Torah de Menahem de Lonzano (Madrid 1980) págs. 48-49. 
Todos los manuscritos españoles que tratamos, así como L y Or 4445, tienen la lectura de BA.

En Num 3,27 también se alude a dos de los códices modelo. En la palabra העָזיאלי la masora dice: «en el Hil·lelí y en el Zambuki está corregido y puntúa el áyin con patah». Norzi y Lonzano afirman que debe llevar solamente qames y que es hatef porque el zayîn lleva dages. Coinciden con esta noticia las lecturas de L, Or 4445, G-II-8, M1, M2 y Or 2201.

Finalmente, el pasaje antes aludido de Deut $34,4{ }^{32}$ se refiere también a los mismos códices modelo.

Haciendo referencia al Hil.lelí hay tres casos que afectan a la vocalización con patah o qames. Son Gen 8,21, 41,50 y Lev 17,3. En el primero de ellos, acerca de וּרָ dice su masora que en el Hil.lelí es con patah. Norzi afirma que debe vocalizar con qames, pero que ha visto en el margen de un manuscrito que en el Hil.lelí es con patah. Lonzano corrobora esta afirmación. Tanto L y Or 4445 como los manuscritos españoles vocalizan con qames.

Gen 41,50 alude a una diferencia entre BA y BN. Acerca de דํㅣ dice la nota que BN escribe ?ִ mientras que BA lo escribe con patah; su masora dice que es dos veces con qames y que también es así en el Hil lelí. Norzi escribe: «en todos los códices de Sefarad el lamed es con qames y la masora dice: una sola vez con qames. Pero es difícil admitirlo porque, según $\mathrm{BA}$, es con patah. El Rab ha-Pe álîm dice: $\mathrm{BA}$ es con patah y $\mathrm{BN}$ con qames. Pero he encontrado otra masora que dice: dos veces con qames» ${ }^{33}$. En este caso, L, Or 4445 y M2 conciden en vocalizar con patah; pero M1 y Or 2201 vocalizan con qames. Una vez más, los dos códices españoles más antiguos coinciden entre sí, al mismo tiempo que con la opinión de Norzi, aunque discrepando de la lectura de BA.

\footnotetext{
32 Vid. supra.

${ }^{33}$ El otro caso es Iob 5,7.
} 
El caso de Lev 17,3 se refiere a la palabra ישחָ, cuya masora anota que se escribe una sóla vez y con qames, pero que en el Hillelí es con patah. Lonzano afirma que en la mayoría de los códices de Sefarad es con patah. Sin embargo, por lo que se refiere a los demás manuscritos que aquí se estudian, M1 y Or 2201 vocalizan con patah, mientras que M2 lo hace con qames. Su masora dice: «es caso único y tiene qames». L y Or 4445 lo escriben también con patah.

Además de los casos que ya hemos visto referidos al Codex Zambuki, hay otros dos que aluden al hatef: Gen 9,14 y Ex 15,2. En el primero de los casos, acerca de la palabra בְִּ dice su masora: «en el Zambuki esta palabra. Dice: «en los códices de Sefarad y en el Hil.lelí el nûn [primero] es con šewa' solamente, pero en el Zambuki lleva š̌wa ' y patah y así está escrito en el 'ôr Torah. Yo creo que es una variante que hay en los códices respecto a palabras que tienen dos letras

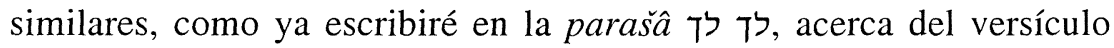
[Gen 12,3]. Allí se verá. Y escribió Rabí David Qimhi que es un verbo daguesado y aligerado de forma inusual». Lonzano afirma igualmente que tanto en los códices de Sefarad como en el Hillelí el nûn lleva solamente š̌wa'. Tanto los manuscritos españoles como L y Or 4445 coinciden con esta vocalización.

El segundo caso, Ex 15,2, en la palabra עִ la nota dice que en el Zambuki es עy. También en este caso Norzi dice al respecto: «el ayin lleva qames hatef por causa del dageš del zayîn para mostrar la falta de la segunda radical...», y añade a continuación otros ejemplos. Sin embargo, Lonzano afirma que el ayîn debe llevar qames solamente. El texto falta en M1, pero el resto de los manuscritos vocalizan el ayîn con qames.

Or $2201^{34}$

Este manuscrito que se conserva en la British Library consta de 368 folios y contiene toda la Biblia Hebrea. Está escrito en letra

\footnotetext{
${ }^{34}$ Para una descripción detallada del ms. véase Ch. D. Ginsburg, Introduction..., págs. 667 ss.
} 
cuadrada sefardí a tres columnas y la masora ocupa los espacios intercolumnares y los márgenes superior e inferior, en la forma acostumbrada. Según el colofón que aparece en el fol. 184r, está fechado en Toledo en 1246; por lo tanto, se trata del más antiguo de los que nos ocupamos aquí.

En los márgenes de este manuscrito apenas aparecen referencias a códices modelo. Solamente he podido encontrar cuatro, dos en el libro de Génesis, una en Números y una cuarta en Deuteronomio, todas ellas citando al Codex Hil.lelí. Es decir, las notas que aparecen en este códice presentan similitudes con las del M1 en cuanto a cantidad y apariencia, ya que también son muy escuetas.

Los dos casos de Génesis y el de Números se refieren a variantes vocálicas. En Gen 5,5, acerca de la palabra el Hil-lelí lleva patah. Esta lectura coincide con la de G-II-8, M1, M2 y Or 2626-28, por lo que Or 2201 queda solo en su vocalización. En Gen 42,16 se refiẻre a la palabra ח̣אסר. Afirma su nota que el Hil.lelí vocaliza con segôl.

Los manuscritos españoles vocalizan igualmente con sêrê, excepto G-II-8, que lo hace con segôl, mientras que la masora de M1 dice que es un caso único. El caso de Núm 34,11 aparecía ya en el manucrito Or 2626-28 ${ }^{35}$, coincidiendo en la noticia que allí tenía.

En Deut 31,1 se afirma que en el Hil-lelí no existe parašâ. Este caso está atestiguado en Norzi, quien afirma que debe haber parašâ abierta y, de hecho, la tienen todos los manuscritos aquí estudiados, así como L y Or 4445.

A partir del estudio realizado en estos cinco manuscritos españoles, se pueden deducir las siguientes conclusiones:

- Los códices españoles aquí estudiados citan en sus masoras del Pentateuco lecturas de los códices modelo, aunque solamente refiriéndose al Hil·lelí, al Zambuki y al Mûggah, además de otros anónimos.

35 Véase pág. 366. 
- Los manuscritos Or 2201, M1, M2 y, en general, el Or 2626-28 dan las noticias de forma mucho más escueta que el G-II-8. Podría decirse que lo hacen con estilo masorético.

- Existen repetidamente varias coincidencias entre los dos manuscritos españoles más antiguos, M1 y Or 2201, frente a los demás. Entre ellas se pueden citar:

- En los códices M1 y Or 2201, las noticias que hacen referencia a los códices modelo son siempre de segunda mano. En menor medida en el M2, y nunca en el G-II-8 ni en el Or 2626-28.

- En cuatro ocasiones, estos manuscritos, M2 y G-II-8, comparten la misma lectura frente a todos los demás (Gen 41,50, Ex 37,24, Lev 17, 3 y Deut 3,16).

- El códice M2 registra el mayor índice de discrepancias con los códices españoles, quedando solo frente a los demás textos en seis ocasiones (Gen 18,17; 46,29; Ex 29,43; 36,7; Lev 26,39 y Deut 32,5). En otra ocasión, Lev 17,3, comparte su texto con Or 2626-28 frente a los demás.

- El códice M1 queda solo frente al resto de manuscritos en una sola ocasión, Num 10,10. El códice G-II-8 queda solo frente al resto en dos ocasiones, Gen 42,16 y Num 34,28.

- Las noticias afectan generalmente a grafías plenas o defectivas y a puntuaciones. Muy escasas son las referentes a otro tipo de variantes.

- A veces, el texto del manuscrito ha sido corregido para hacerlo coincidir con la información que aparece en su MP. 


\section{LISTA DE PASAJES}

\section{G-II-8}

Mûggah

Gen $4,13 *$

יש ספרים מדויקים מנשא חסר ובספר מוגהi כתi מנשאט מל ומסור עליה יב מל בתו משו משו

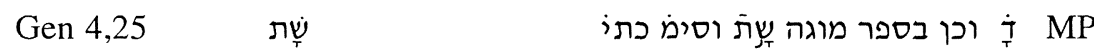

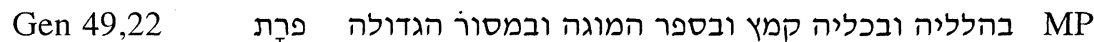
אשכחת דאיניו פת עד יבא ויורה צדק (Os 10,12)

Ex 37,24* רכּ בספ מוגה כְבַר כת לפי שהוא סמיך MP

Ex 39,4 על שני במוג אל שני MP

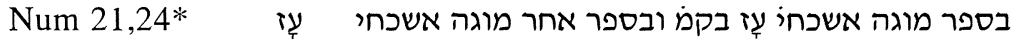

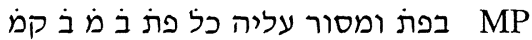

Hil.lelí

Gen 4,23 האזנה ויש נקודי האזנה בסגול וכן בהללי MP

Gen 11,29 MP

Gen $18,17 *$ הַpִ

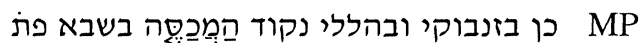

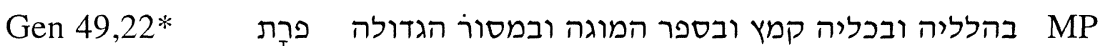
אשכחת דאיניו פת עד יבא ויורה צדק (Os 10,12)

Ex 30,14* מבקּן בהללי מבִּן MPP

Zambuki

Gen 4,17

Gen 9,6 בצֶלם

Gen 12,15 ניהלְלו

Gen 16,11
ב马
בזנבוקי כתֹי בנִה בצרי MP ובספ זנבוקי בצִלם בצרי

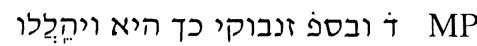
בן דגש בזנבוקי MP 
Gen 18,17* הַמְכַַסְּה

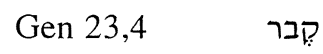

Num 10,36

Num 11,1* כמתאנְנִים

Anónimos

Gen $4,13 *$

מנשא

Gen 25,6* הפילגשים

כשבית כשי

איבֶיך

M1

Mûggah

Lev $4,31 * \quad$

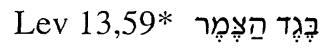

Lev 14,49* ואזב

אוֹיְביכם

Deut $3,16^{*} \quad\left(1^{\circ}\right)$ (p m וער עד (1)

Deut 22,19 כסף

Deut $28,1^{*}$

Deut $32,5^{*}$ לא

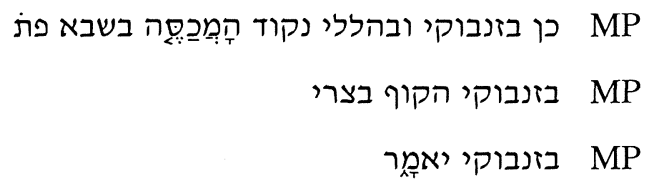

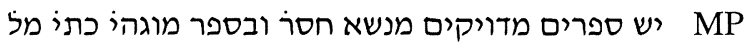
ומסור עליה יב מש בתום מדוקי משו

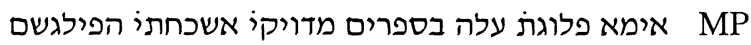
חס יוד בתר ולא נתקן עד שיבא אליהו

ס ס ס כשביות

אשכחתיה בספרים מדוייקi איביך מל יוד ומסיר (DP עליה ב חס כי תצא למלחמה קדמא (Deut 20,1)

ודין
ובמוגה מוגהין חֶלֶב MP

מוגה MP

במוגה ואזוב מל MP

מוגה MP

MP

MP

במוגה שמע חס MP

MP

ד ד דגשו 


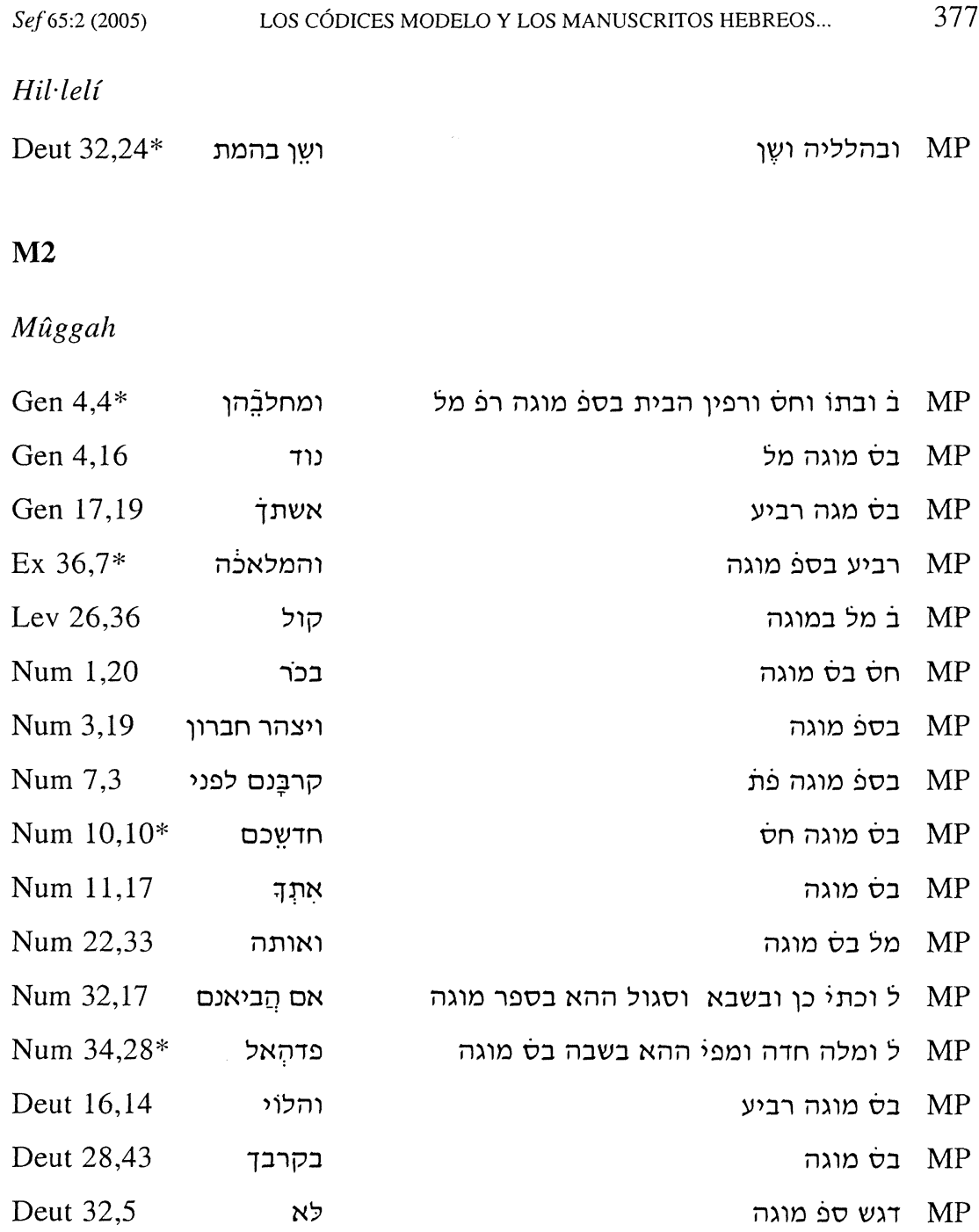

\section{Or 2626-28}

Mûggah

Gen $42,8^{*}$ הכרהו (p m (כירור) במוגה ל חס במסורה מוגה א חס וא מל MP (Iob 2,12)

Gen $49,8 *$ יודוך במוגה ברא׳ הדף וסi ביה שמו MP 
Gen $49,11 *$

כבְבְס

Ex 14,28*

הבאים

Ex 15,20

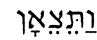

Ex 20,19

רבּุ

Ex 25,39

Ex 29,43*

Lev 11,19

Lev 15,22

Lev 16,8*

Lev 21,8

Lev 23,17

Num $1,22 *$

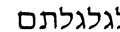

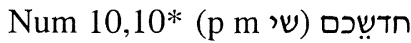

Num 13,30

]

Num $24,5^{*}$

מה־טבו

Num 36,9

למטִה

Deut 2,8

그ำ ำ

Deut 4,26

העידתי

Deut $7,13^{*}$

שֵַ

Deut 9,14

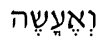

Deut 10,13

Deut 18,1

Deut 19,14

Deut 27,8

Deut 30,7

Deut $31,28 *$
לִׁמ́

זُהוה

תנחל

รָณ

אָּת

ואעידה
S MP

במוגה ברא הדף וסימ ביה שמו

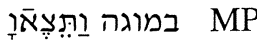

במוגה בַבְּר MP

במוגה קמ MP

S פת ובמוג קמ MP

במוגה הדוכיפָת בקמ

במוגה בכל בחלם MP

במוגה ברא הדף וסימ בتה שמו

MP

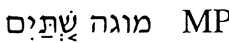

במוגה למד מגידא מכל למד MP

MP

במוגה ויהס כלו נקוֹ פת MP

במוגה ברא הדף וסימ בتיה שמוו MP

במוגה נגרד הסגול ונשא צרי MP

אשכחית במוגה -ב MP

MP

במוגה שגָר MP

MP

במוגה לשֶמִר MP

MP

MP

במוגה אֶָת MP

בהללי ובזנבוקי אֶת ובמוגה במאריך MP

במוגה ברא הדף וסימ ב־יה שמוו MP 


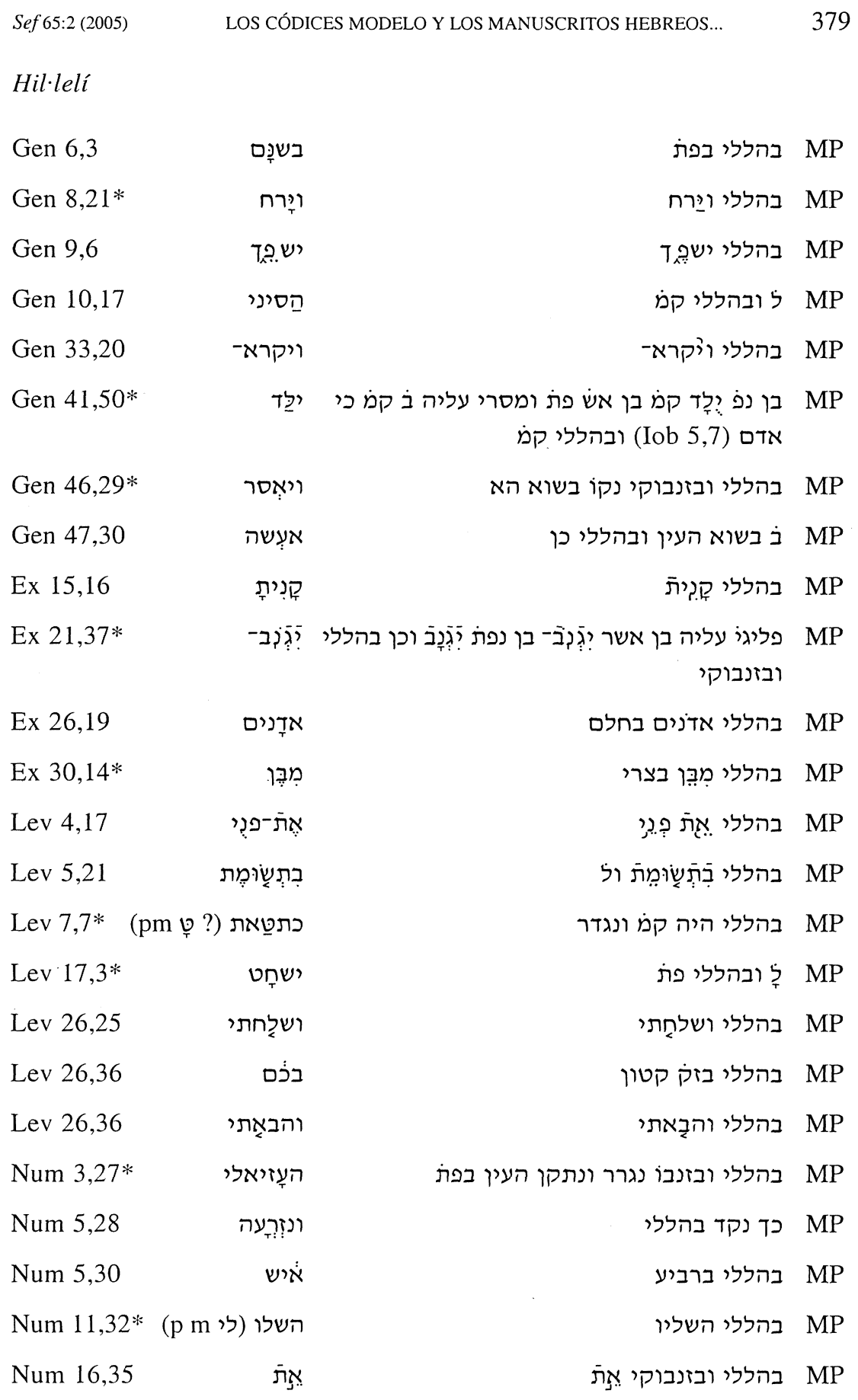


380

Num 31,26

Num 34,11*

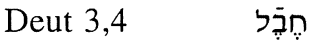

Deut 3,13 חקרָל

Deut 5,26

תד̄רו Deut 12,11 *

Deut 23,3 군

Deut 30,7

בעיניך ב ב

\section{Zambuki}

Gen 4,17 בנקינה

Gen $9,14 *$

Gen 42,2

Gen 42,21 בהתחְנְנו

Gen 43,10

Gen 43,21

Gen 45,3 העוד

Gen 45,10

Gen 46,29* ויאֶר

יקהַת Gen 49,10

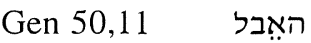

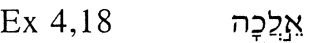

Ex 7,12

Ex 10,8

Ex 10,26

נקח
M. ${ }^{a}$ TERESA ORTEGA MONASTERIO

Sef 65:2 (2005)

בהללי כך אָת MP

בהללי כַּנְרֶת

בהללי חֶֶַל MP

בהללי חֶֶַל MP

כך בהללי ובזנבוקי MP

רذ ומשקלו ותתצו הבתים (Is 22,10) וכן בהללי MP

בהללי:יָבאד-מלעו

בהללי ובזנבוקי אֶת ובמוגה במאריך MP

בהללי פעיניך דגש ובזנבוקי רפ MP 


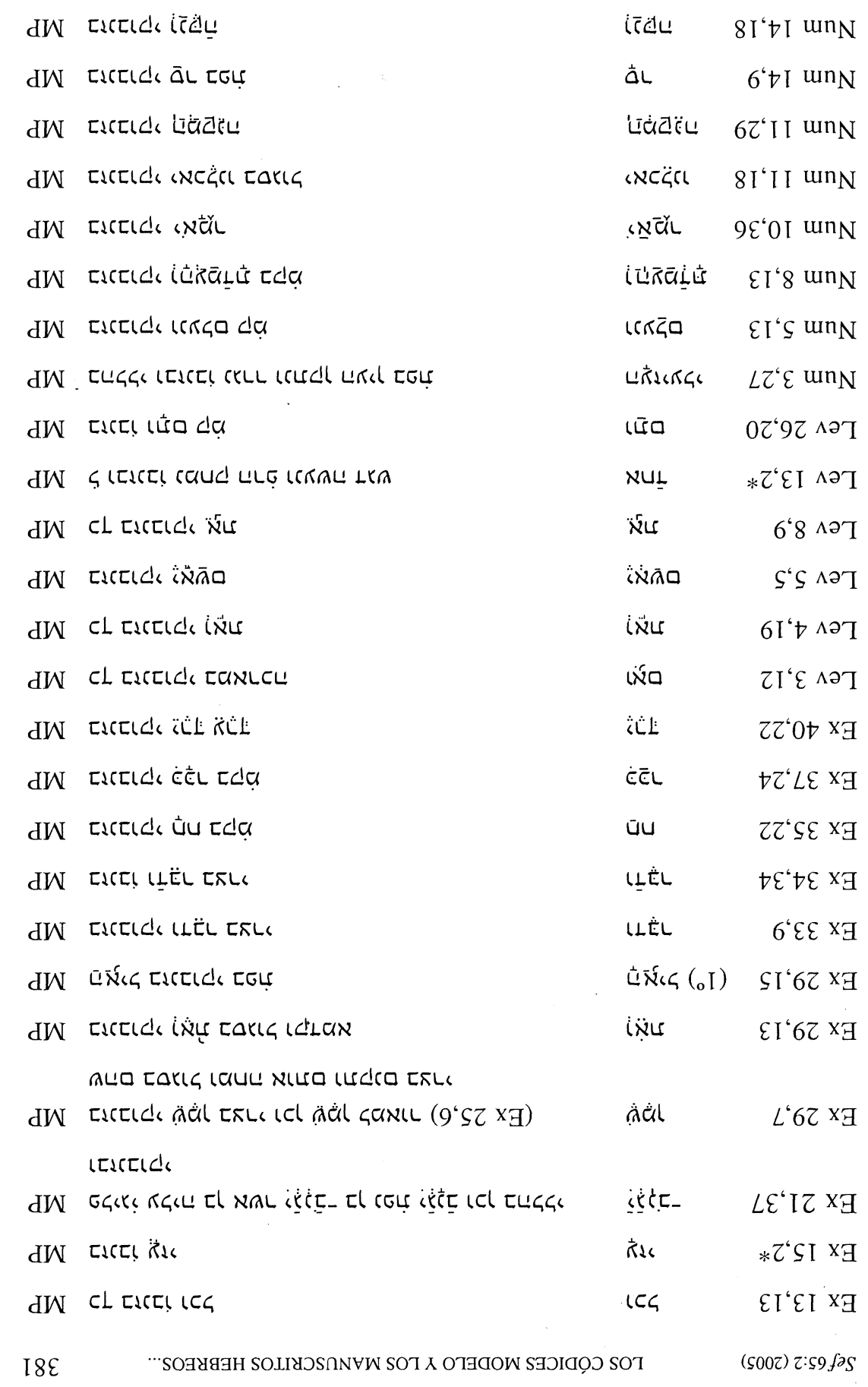




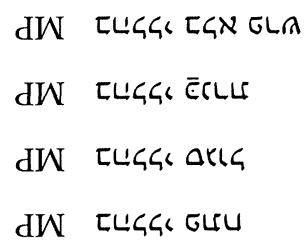

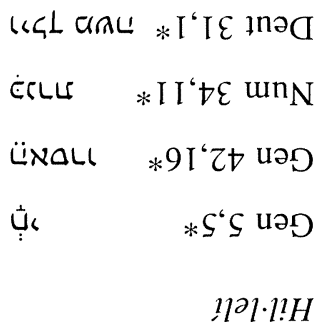

I0zz

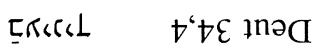

L'OE Inad

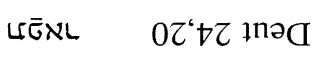

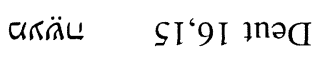

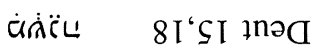

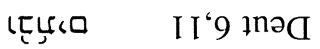

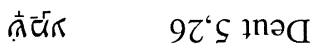

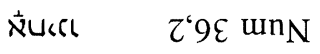

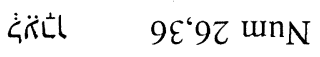

iڤڤ

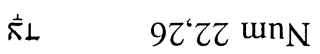

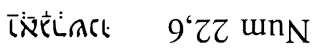

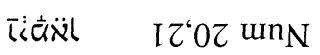

ī̌RLLL! S'LI UnN

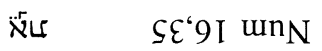

$\tau 8 \mathcal{E}$ 


\section{RESUMEN}

La importancia de los manuscritos hebreos bíblicos conservados en bibliotecas españolas es bien conocida. Algunos de ellos, por ejemplo, han sido utilizados en la composición de famosas biblias, tales como la Políglota Complutense o la Biblia Regia.

A pesar de la aparente similitud de la masora de los manuscritos españoles más significativos, el estilo y la información que proporcionan muestran algunas diferencias. En este artículo he seleccionado algunos manuscritos españoles relevantes y he analizado las notas que aparecen en las masoras del Pentateuco acerca de estos códices modelo.

PALABRAS CLAVE: Masora, manuscritos hebreos bíblicos españoles, códices modelo.

\section{SUMMARY}

The importance of Biblical Hebrew manuscripts preserved in Spanish libraries is well known. Some of them, for example, were used in the edition of celebrated Polyglote Bibles, such as the Complutensian or Antwerp Bible.

Despite the apparent similarity of the Masorah of most significant Spanish manuscripts, the style and the information they provide show some differences. In the present article I have selected some important Spanish manuscripts, and studied the notes in the Masorah of the Pentateuch referring to the so-called Model Codices.

KEYwORDS: Masorah, Biblical Hebrew Spanish manuscripts, Model Codices. 